\title{
BMJ Open Is neighbourhood social cohesion associated with subjective well-being for older Chinese people? The neighbourhood social cohesion study
}

\author{
Ruby Yu, ${ }^{\oplus 1,2}$ Osbert Cheung, ${ }^{1}$ Jason Leung, ${ }^{3}$ Cecilia Tong, ${ }^{2}$ Kevin Lau, ${ }^{2,4}$ \\ Johnny Cheung, ${ }^{2}$ Jean Woo ${ }^{1,2}$
}

To cite: Yu R, Cheung 0 , Leung J, et al. Is neighbourhood social cohesion associated with subjective well-being for older Chinese people? The neighbourhood social cohesion study. BMJ Open 2019;9:e023332. doi:10.1136/ bmjopen-2018-023332

- Prepublication history for this paper is available online. To view these files, please visit the journal online (http://dx.doi org/10.1136/bmjopen-2018023332).

Received 1 April 2018 Revised 31 January 2019 Accepted 25 February 2019

Check for updates

(C) Author(s) (or their employer(s)) 2019. Re-use permitted under CC BY-NC. No commercial re-use. See rights and permissions. Published by BMJ.

${ }^{1}$ Department of Medicine \& Therapeutics, Faculty of Medicine, The Chinese University of Hong Kong, Hong Kong

${ }^{2}$ CUHK Jockey Club Institute of Ageing, The Chinese University of Hong Kong, Hong Kong

${ }^{3}$ CUHK Jockey Club Centre for Osteoporosis Care and Control, The Chinese University of Hong Kong, Hong Kong

${ }^{4}$ Institute of Future Cities, The Chinese University of Hong Kong, Hong Kong

Correspondence to

Dr Ruby Yu;

rubyyu@cuhk.edu.hk

\section{ABSTRACT}

Objectives To evaluate the psychometric properties of the Hong Kong version of Neighbourhood Cohesion Instrument (HK-NCI) and examine whether neighbourhood social cohesion as measured using HK-NCl would be associated with evaluative, hedonic and eudaemonic wellbeing.

Design A validation analysis followed by a cross-sectional analysis of a community-based survey.

Setting Communities in two districts (Sha Tin and Tai Po) in Hong Kong.

Participants 301 community-dwelling Chinese men and women aged 60 years and older normally residing in Sha Tin or Tai Po for not less than six consecutive months at the time of participation in the study were interviewed.

Measurements Neighbourhood social cohesion was measured using the 15-item HK-NCl. The Social Cohesion Scale (SCS) and the Brief Sense of Community Scale (BSCS) were administered for assessing the validity of the HK-NCI. Evaluative (life satisfaction), hedonic (feelings of happiness) and eudaemonic well-being (sense of purpose and meaning in life) were examined. Socio-demographic characteristics, lifestyle and health behaviours, medical history, and neighbourhood characteristics were used as covariates.

Results For homogeneity, internal consistency of HK-NCI $(\alpha=0.813)$ was good. For stability (test-retest reliability), the averages of mean scores of the 15 items suggested an acceptable repeatability with an intra-class correlation coefficient $=0.701(95 \% \mathrm{Cl} 0.497$ to 0.832 ). $\mathrm{HK}-\mathrm{NCl}$ was correlated with SCS $(r=0.515-0.635, p<0.001)$ and BSCS $(r=0.500-0.612, p<0.001)$. Neighbourhood social cohesion was positively and independently associated with life satisfaction, feelings of happiness and sense of purpose and meaning in life (all $p$ values $<0.05$ ). Stratified analyses indicated that neighbourhood social cohesion was more strongly associated with all dimensions of subjective wellbeing in 'young-old' subgroup, and with sense of purpose and meaning in life for women.

Conclusion The HK-NCI has adequate levels of internal consistency and test-retest reliability. In addition, higher levels of neighbourhood social cohesion were associated with better subjective well-being among older Chinese people.

\section{Strengths and limitations of this study}

- The study was able to examine multiple dimensions of subjective well-being (evaluative, hedonic and eudaemonic well-being) using a sample of older Chinese.

- The study collected a variety of potential confounding factors including socio-demographic, lifestyle and health behaviours, medical history, and neighbourhood characteristics.

- The study was cross-sectional and therefore impossible to establish casual associations between neighbourhood social cohesion and subjective well-being.

- The results were subject to selection bias as sociable people might be more likely to participate in this study. Self-reported and subjective measurements might cause information bias.

\section{INTRODUCTION}

While advancing age is often accompanied by functional decline, which is negatively associated with well-being, the effect of wellbeing on health is also substantial. Research evidence has demonstrated that low levels of well-being are associated with an increased risk of adverse health outcomes, such as frailty, ${ }^{1}$ Alzheimer's disease ${ }^{2}$ and mortality, ${ }^{3}$ whereas high levels of well-being results in better health and longevity. ${ }^{4}$ Therefore, understanding factors that contribute to wellbeing of older people is important, as this might allow appropriate interventions to be implemented.

Among the contributory factors of wellbeing, socioeconomic characteristics (eg, marital status, income, subjective social status) have been most studied and their contributions to well-being are well established. ${ }^{5}$ However, the role of social contextual factors, in particular social cohesion, remains understudied. To date, there is no 
consensus regarding the definition of social cohesion. Nevertheless, social cohesion can be understood as 'the extent of connectedness and solidarity among groups in society'. ${ }^{6}$ In an extensive review, social cohesion has been redefined as 'a state of affairs concerning both the vertical (the relationship between the state and society) and the horizontal (the interactions among different individuals and groups in society) interactions among members of society as characterised by a set of attitudes and norms that includes trust, a sense of belonging and the willingness to participate and help, as well as their behavioural manifestations'. 7 Recently, three essential dimensions of social cohesion including social relations, identification with the geographical unit and orientation towards the common good have also been suggested. ${ }^{8}$ In a nutshell, neighbourhoods with high levels of social cohesion are expected to generate values such as interpersonal trust and norms of reciprocity, which may be beneficial to the health and well-being of people within the neighbourhoods.

In recent years, the role of neighbourhood social cohesion has gained much prominence in the public health literature because of its associations with various health outcomes, such as self-rated health, ${ }^{9}$ frailty, ${ }^{10}$ myocardial infarction, ${ }^{11}$ stroke ${ }^{12}$ and mortality. ${ }^{13}$ Furthermore, neighbourhood social cohesion has been associated with mental health and well-being, with low levels of neighbourhood social cohesion associated with increased depression, stress and anxiety, ${ }^{14}{ }^{15}$ whereas high levels of neighbourhood social cohesion are associated with better well-being. ${ }^{16-20}$ However, the mechanisms responsible for the association between neighbourhood social cohesion and well-being are not certain. There are several pathways that may link neighbourhood social cohesion to positive well-being. For example, perceived neighbourhood social cohesion, particularly relationships with neighbours could be viewed as a type of social support, which might affect health outcomes and well-being by facilitating access to health information and services. ${ }^{21}$ Neighbourhood social cohesion might also influence well-being through the enhancement of mutual trust and emotional support. ${ }^{22}$ A number of qualitative studies have indicated that neighbours can serve as a central source of support and meaning in adults' lives, ${ }^{23}$ in particular for people who have experienced a sense of loss. ${ }^{24}$ Furthermore, neighbourhood social cohesion can offset the negative effects of stressors on mental health by facilitating access to networks and services that influence health, social and emotional support. For example, in a Japanese prospective study, high neighbourhood cohesion partially reduced the deleterious effect of anticipated daily stressors on older residents' depressive mood. ${ }^{25}$ Evidence from a British longitudinal cohort study has also suggested that the adverse effect of neighbourhood deprivation on mental health was significantly reduced in high social cohesion neighbourhoods. ${ }^{26}$ However, the majority of the studies examining the link between neighbourhood social cohesion and well-being have not focused on older people, who usually spend more time in their neighbourhoods, as dependence on neighbourhood resources increases with age. ${ }^{27} 28$

Maintaining well-being at advanced ages is growing in importance as well-being is relative to health and quality of life as people age. ${ }^{29}$ However, levels of well-being of older people in Hong Kong were relatively low, based on a comparative analysis of a multi-dimensional index assessing the social and economic well-being of elderly populations in over 90 countries. $^{30}$ Therefore, it is important to examine whether levels of neighbourhood social cohesion is one factor contributing to low levels of well-being among older people living in Hong Kong.

In order to examine the association between neighbourhood social cohesion and well-being in older Chinese people, relevant measures of neighbourhood social cohesion that are culturally appropriate are needed. A literature search on the measurement of perceived neighbourhood social cohesion found various validated inventories and scales, for example, the Neighbourhood Cohesion Instrument (NCI), ${ }^{31}$ the Social Cohesion Scale (SCS) ${ }^{32}$ and the 4-item scale developed and tested for the use in two nationally representative studies of older adults (the Health and Retirement Study and the English Longitudinal Study of Aging) ${ }^{33}$ However, these inventories or scales have not been adapted for an older Chinese population.

In the present study, we attempted to adapt the Hong Kong version of NCI (HK-NCI) that is linguistically valid for older Chinese and to evaluate the psychometric properties of HK-NCI. We also examined whether neighbourhood social cohesion and its two domains (social cohesion and neighbourhood belonging) as measured using HK-NCI would be associated with three dimensions of subjective well-being, including evaluative (life satisfaction), hedonic (feelings of happiness) and eudaemonic well-being (sense of purpose and meaning in life) in a sample of community-dwelling older Chinese people living in seven selected neighbourhoods in two districts of Hong Kong, controlling for individual-level and neighbourhood-level characteristics. Furthermore, it has been suggested that age and gender differences exist in the association between social participation and health, ${ }^{34}$ both of which are factors associated with neighbourhood social cohesion and subjective well-being. Therefore, it is plausible that age and gender differences may also exist in the association between neighbourhood social cohesion and subjective well-being. Hence, we also examined whether the association between neighbourhood social cohesion and subjective well-being varied by age and gender.

\section{METHODS}

\section{Sampling}

The study was established in order to investigate the impact of neighbourhood social cohesion on health and well-being of older people. A cross-sectional survey of 
older people was conducted between June and August 2017 to validate HK-NCI, and to examine the association between neighbourhood social cohesion and subjective well-being. The sampling method has been described by Yu et al. ${ }^{35}$ In brief, a convenience sampling method was employed and the survey was designed to interview approximately 150 community-dwelling local residents aged 60 years and above from each of the two districts (Sha Tin and Tai Po) in Hong Kong, where the whole territory is divided into 18 districts at present. Both Sha Tin and Tai Po are located in the New Territories of Hong Kong, with their population estimated at 659794 and 303926 in 2016, respectively. ${ }^{36}$ Considering the socio-economic heterogeneity across these geographic regions, seven neighbourhoods in the two districts were chosen according to the neighbourhood types (ranging from mixed-use town centres to areas covering traditional villages) and the predominant type of housing (ranging from private housing to public housing) which were acting as proxies for socioeconomic status. The seven neighbourhoods were (1) Sha Tin Town Centre; (2) Lek Yuen and Wo Che; (3) Ma On Shan Town Centre, Yiu On and Heng On; (4) Yee Fu and Kwong Fuk; (5) Tai Po Cental; (6) Tai Po Hui and Old Market; and (7) Lam Tsuen Valley, which are represented by a range of typical housing types in different settings (private/subsided/public housing in town centres, tenement housing in old urban core, village house in low-density to mid-density areas). For example, Sha Tin Town Centre, Ma On Shan Town Centre and Tai Po Cental are areas which accommodate private, subsided, and public housing, supplemented with commercial and open space to form a mixed-use development pattern. Lek Yuen, Wo Che, Yiu On, Heng On, Yee Fu and Kwong Fuk are areas which accommodate predominantly public rental housing supported by essential infrastructure and community facilities. Tai Po Hui and Old Market are clustered with tenement housing. Lam Tsuen Valley is situated in the west of Tai Po, an area covering both traditional villages and new residential housing. Hence, the study population would include older people living in both urban and rural areas with different socioeconomic profiles. For this study, a neighbourhood was defined as a spatial unit within which residents share similar socioeconomic and cultural identities. Neighbourhood boundaries were delineated using the government web map portal, GeoInfo Map (http://www1.map.gov.hk/gih3/ view/index.jsp). Major roads and waterways served as barriers to movement and communication and therefore served as logical boundaries of the neighbourhood.

\section{Participants}

Three hundred and one community-dwelling Chinese men and women aged 60 years and older were recruited in the survey. Participants were recruited by placing recruitment notices in housing estates and elderly community centres. Several talks were also given at the centres explaining the purpose of the study and the interviews to be carried out. An age-stratified sample of volunteers was recruited, so that approximately $50 \%$ of the participants would be aged $60-69,30 \%$ would be aged $70-79$ and $20 \%$ would be aged 80 years and older, according to the age structure of the mid-year population (aged 60 years and older) of Hong Kong in 2016. To be eligible to take part in the survey, participants needed to be aged 60 years and older, able to walk, able to speak Cantonese, and normally residing in Sha Tin or Tai Po for not less than six consecutive months at the time of participation in the study. Institutionalised persons, foreign domestic helpers, and individuals who were mentally unable to communicate were excluded. A team of trained research assistant administered the questionnaire face-to-face for each participant. All participants gave written consent. Furthermore, a random sub sample of 38 participants was reinterviewed over the telephone for a reliability test after a 4 -week interval.

\section{Adaptation of the neighbourhood cohesion inventory}

The NCI, originally developed by Buckner ${ }^{31}$ and modified by Fone et al, ${ }^{37}{ }^{38}$ has been used cross-culturally with good internal consistency (Cronbach's $\alpha$ : 0.840.95). ${ }^{11} 28{ }^{39}$ In the present study, the NCI was translated from English to Cantonese involving two independent forward translations (from English to Cantonese), after which a Cantonese native speaker reconciled the two Cantonese translated versions. A back translation was then performed from Cantonese to English. The original English version and the back translated version were examined by a group of bilingual experts whom examined and resolved discrepancies in the meaning of the scale items. A pilot test was conducted among 10 older people with the trial Hong Kong version of NCI (HK-NCI), and modifications were made according to the participants' feedback on the items.

The HK-NCI consists of two subscales measuring social cohesion [eight items, HK-NCI-SC (social cohesion)] and neighbourhood belonging [seven items, HK-NCI-NB (neighbourhood belonging)]. All items were measured on a 5-point Likert scale from 1 (strongly disagree) to 5 (strongly agree). Total scores of HK-NCI were computed by taking the average of the 15 items (items 7 and 11 were reverse scored). Higher scores on the HK-NCI represent higher degrees of perceived neighbourhood social cohesion.

To assess the construct validity of the HK-NCI, the $\mathrm{SCS}^{32}$ and the Brief Sense of Community Scale (BSCS) ${ }^{40}$ were administered to each participant during the same interview. The 5-item SCS was designed to measure neighbourhood social cohesion. Participants were asked how strongly they agreed with the following statements: 'people around here are willing to help their neighbours', 'this is a close-knit neighbourhood', 'people in this neighbourhood can be trusted', 'people in this neighbourhood generally do not get along with each other' and 'people in this neighbourhood do not share the same values'. Items were measured on a 5-point Likert scale from 1 (strongly disagree) to 5 (strongly agree). Total scores were computed by taking the average of the five items 
(the last two statements were reverse coded). Higher scores on the SCS represent higher degrees of perceived neighbourhood social cohesion. The 8-item BSCS was designed to assess the dimensions of needs fulfilment, group membership, influence and emotional connection defined in the McMillan and Chavis' (ibid.) model. Items were measured on a 5-point Likert scale from 1 (strongly disagree) to 5 (strongly agree). Total scores were computed by taking the sum of the eight items. Higher scores on the BSCS represent higher degrees of perceived sense of community.

\section{Measures of subjective well-being}

To examine the association between neighbourhood social cohesion and subjective well-being, three aspects of subjective well-being including evaluative well-being (life satisfaction), hedonic well-being (feelings of happiness) and eudaemonic well-being (sense of purpose and meaning in life) were measured. Life satisfaction was measured with a single item, 'Overall, how satisfied are you with life as a whole these days?' which participants rated on a scale from 0 as 'not at all satisfied' to 10 as 'completely satisfied'. ${ }^{41}$ Feelings of happiness was measured with a single item, 'How happy did you feel yesterday?' which participants rated on a scale from 0 as 'not at all happy' to 10 as 'completely happy'. ${ }^{41}$ Sense of purpose and meaning in life were measured with a single item, 'Do you feel your life has an important purpose or meaning?' which participants rated on a scale from 0 as 'not at all worthwhile' to 10 as 'completely worthwhile'.

\section{Covariates}

Individual-level characteristics include socio-demographics (age, gender, marital status, education, employment status, income, type of housing and length of residence), lifestyle and health behaviours (smoking, alcohol intake, and physical activity), and medical history (number of self-reported chronic health conditions). Neighbourhood-level characteristics include geographic size, number of older persons, and number of elderly and social centres in each of the selected neighbourhoods.

\section{Data analysis}

Continuous variables are presented as mean values and $\mathrm{SD}$, and the categorical variables are presented as number and percentage. T-test and ANOVA were used to examine the group differences in HK-NCI score. To evaluate the psychometric properties of HK-NCI, first, internal consistency analyses (Cronbach's $\alpha$ ) were conducted to test homogeneity of the HK-NCI scale and its two subscales. Second, the stability (test-retest reliability) of the HK-NCI scale was determined by intra-class correlation coefficients (ICC). Third, construct validity was estimated by Pearson's correlation coefficients of total and subscores of HK-NCI with total scores of SCS and BSCS. To examine whether neighbourhood social cohesion and its two domains 'social cohesion' and 'neighbourhood belonging' as measured using HK-NCI would be associated with the three dimensions of subjective well-being, two-level hierarchical linear regressions of individual subjects at level 1 and the seven neighbourhoods at level 2 were performed, with model 1 being the crude model, model 2 adjusting for socio-demographic characteristics (age, gender, marital status, education, employment status, income, type of housing and length of residence), model 3 adjusting for the covariates included in model 2 with additional adjustments for lifestyle and health behaviours (physical activity, smoking and alcohol intake), and medical history (number of self-reported chronic health conditions), and model 4 further adjusting for neighbourhood characteristics (geographic size, number of older persons and number of elderly centres in each of the selected neighbourhoods). Unstandardised regression coefficients and $\mathrm{p}$ values were calculated by using a mixed-effect model, putting neighbourhood as random effect. The analyses described above were repeated and stratified by age group (60-69, 70+) and sex. Participants were excluded if there are observations missing for any outcome measure. A $p<0.05$ will be used to denote significant difference. All analyses were performed with SPSS V.24.0 (SPSS) and the statistical package SAS V.9.4 (SAS Institute).

\section{Patient and public involvement}

This research was done with public involvement. Patient and public involvement (PPI) representatives were invited to comment on the research instrument and were consulted to develop the revised version (HK-NCI). However, PPI was not invited to contribute to the writing or editing of this document for readability or accuracy.

\section{RESULTS}

\section{Characteristics of the participants}

Table 1 presents characteristics of the participants. A total of 301 Chinese men and women aged between 60 years and 95 years have been interviewed. The mean age of the participants was 72 years, with the majority aged from 60 to $69(46.5 \%)$. Among these participants, $59.8 \%$ were women, $68.0 \%$ were married and $44.9 \%$ received at least secondary education. In terms of type of housing, most participants (89.4\%) lived in urban areas while only $10.6 \%$ lived in rural areas (village housing). The mean scores of life satisfaction, feelings of happiness and sense of purpose and meaning in life were 7.4, 7.8 and 7.9, respectively. Furthermore, higher HK-NCI scores were observed among those who lived in village housing $(\mathrm{p}<0.001)$ or had higher levels of physical activity $(\mathrm{P}<0.001)$.

\section{Psychometric properties of the HK-NCI}

The mean score of HK-NCI was 3.8, with higher subscores in 'neighbourhood belonging' (4.2), but lower subscore in 'social cohesion' (3.5). For homogeneity, internal reliabilities of total 15 -item HK-NCI $(\alpha=0.813)$, HK-NCI-SC $(\alpha=0.763)$, HK-NCI-NB $(\alpha=0.715)$ were good. For stability (test-retest reliability), the averages of mean scores of the 15 items suggested an acceptable repeatability with an 
Table 1 Characteristics of the study population $(n=301)$

\section{HK-NCI}

\begin{tabular}{|c|c|c|c|}
\hline \multirow[b]{2}{*}{ Variables } & \multirow{2}{*}{$\begin{array}{l}\text { Mean } \pm \text { SD / } \\
\text { N (\%) }\end{array}$} & score & \multirow[b]{2}{*}{$P$ value } \\
\hline & & Mean \pm SD & \\
\hline \multicolumn{4}{|l|}{ Age group, years (range: 60-95) } \\
\hline $60-69$ & $140(46.5)$ & $3.8 \pm 0.5$ & 0.889 \\
\hline $70-79$ & $94(31.2)$ & $3.8 \pm 0.5$ & \\
\hline$\geq 80$ & $67(22.3)$ & $3.8 \pm 0.6$ & \\
\hline \multicolumn{4}{|l|}{ Gender } \\
\hline Men & $121(40.2)$ & $3.7 \pm 0.6$ & 0.067 \\
\hline Women & $180(59.8)$ & $3.8 \pm 0.5$ & \\
\hline \multicolumn{4}{|l|}{ Marital status } \\
\hline Married & $204(68.0)$ & $3.8 \pm 0.5$ & 0.261 \\
\hline $\begin{array}{l}\text { Never/widowed/ } \\
\text { divorced/separated }\end{array}$ & $96(32.0)$ & $3.9 \pm 0.5$ & \\
\hline \multicolumn{4}{|l|}{ Education } \\
\hline $\begin{array}{l}\text { Uneducated/pre-school/ } \\
\text { primary education }\end{array}$ & $166(55.2)$ & $3.8 \pm 0.6$ & 0.256 \\
\hline Secondary/tertiary education & $135(44.9)$ & $3.8 \pm 0.5$ & \\
\hline
\end{tabular}

Employment

\begin{tabular}{|c|c|c|c|}
\hline Unemployed & $277(92.3)$ & $3.8 \pm 0.5$ & 0.719 \\
\hline Employed (part-time/full-time) & $23(7.7)$ & $3.8 \pm 0.6$ & \\
\hline \multicolumn{4}{|l|}{ Income, Hong Kong dollars } \\
\hline$<4000$ & $91(30.7)$ & $3.8 \pm 0.5$ & 0.341 \\
\hline $4000-7999$ & $98(33.1)$ & $3.7 \pm 0.5$ & \\
\hline$\geq 8000$ & $107(36.2)$ & $3.8 \pm 0.5$ & \\
\hline \multicolumn{4}{|l|}{ Housing type } \\
\hline Private high-rise housing & $76(25.3)$ & $3.7 \pm 0.4$ & $<0.001$ \\
\hline Tenement housing & $30(10.0)$ & $3.6 \pm 0.6$ & \\
\hline Subsidised housing & $43(14.3)$ & $3.7 \pm 0.5$ & \\
\hline Public housing & $120(39.9)$ & $3.9 \pm 0.5$ & \\
\hline Village housing & $32(10.6)$ & $4.1 \pm 0.6$ & \\
\hline \multicolumn{4}{|l|}{ Living arrangement } \\
\hline Living with others & $244(81.1)$ & $3.8 \pm 0.5$ & 0.839 \\
\hline Living alone & $57(18.9)$ & $3.8 \pm 0.6$ & \\
\hline \multicolumn{4}{|c|}{ Length of residence, years (range: 0.5-78) } \\
\hline$<10$ & $47(15.6)$ & $3.7 \pm 0.6$ & 0.059 \\
\hline $10-19$ & 37 (12.3) & $3.7 \pm 0.6$ & \\
\hline $20-29$ & 100 (33.2) & $3.9 \pm 0.4$ & \\
\hline $30-39$ & $85(28.2)$ & $3.9 \pm 0.5$ & \\
\hline$\geq 40$ & 32 (10.6) & $3.7 \pm 0.6$ & \\
\hline \multicolumn{4}{|l|}{ Current smoker } \\
\hline No & $284(94.7)$ & $3.8 \pm 0.5$ & 0.299 \\
\hline Yes & $16(5.3)$ & $3.7 \pm 0.6$ & \\
\hline \multicolumn{4}{|l|}{ Current drinker } \\
\hline No & $263(87.7)$ & $3.8 \pm 0.5$ & 0.706 \\
\hline Yes & 37 (12.3) & $3.8 \pm 0.5$ & \\
\hline \multicolumn{4}{|l|}{ Physical activity } \\
\hline$<1$ hour/day & 155 (51.5) & $3.7 \pm 0.5$ & $<0.001$ \\
\hline$\geq 1$ hour/day & $146(48.5)$ & $3.9 \pm 0.5$ & \\
\hline
\end{tabular}

Continued
Table 1 Continued

\begin{tabular}{|c|c|c|c|}
\hline & Mean \pm SD / & $\begin{array}{l}\mathrm{HK}-\mathrm{NCl} \\
\text { score } \\
\end{array}$ & \\
\hline Variables & $\mathrm{N}(\%)$ & Mean \pm SD & $P$ value \\
\hline \multicolumn{4}{|l|}{ Medical history } \\
\hline$<5$ diseases & $258(85.7)$ & $3.8 \pm 0.5$ & 0.230 \\
\hline$\geq 5$ diseases & $43(14.3)$ & $3.7 \pm 0.5$ & \\
\hline \multicolumn{4}{|l|}{ Subjective well-being } \\
\hline Life satisfaction & $7.4 \pm 1.9$ & - & - \\
\hline Feelings of happiness & $7.8 \pm 2.1$ & - & - \\
\hline $\begin{array}{l}\text { Sense of purpose and } \\
\text { meaning in life }\end{array}$ & $7.9 \pm 1.7$ & - & - \\
\hline
\end{tabular}

HK-NCl, Hong Kong version of Neighbourhood Cohesion Instrument.

$\mathrm{ICC}=0.701$ ( $\mathrm{n}=38,95 \% \mathrm{CI} 0.497$ to 0.832$)$ (table 2). There were positive correlations of the total and the subscores of HK-NCI with the total score of SCS $(\mathrm{p}<0.001, \mathrm{r}=0.515-$ $0.635)$ and the total score of BSCS $(\mathrm{p}<0.001, \mathrm{r}=0.500$ 0.612) (table 3).

\section{Associations between neighbourhood social cohesion and subjective well-being}

In model 1 (crude model), neighbourhood social cohesion (total score of HK-NCI) was positively associated with all three dimensions of subjective well-being (all $\mathrm{p}$ values $<0.0001)$. Adjustments for socio-demographic characteristics (model 2) and lifestyle and health behaviours, as well as medical history (model 3) did not alter the results (all $\mathrm{p}$ values $<0.0001$ ). Controlling for the additional neighbourhood characteristics including geographic size, number of older persons and number of elderly centres in each of the selected neighbourhoods did not attenuate the associations of neighbourhood social cohesion and subjective well-being (all $p$ values $<0.0001$, model 4 ). Furthermore, the associations of neighbourhood social cohesion with life satisfaction $(\beta=1.079$, $p$ value $<0.0001)$ and feelings of happiness $(\beta=1.080$, $p$ value $<0.0001)$ were stronger than that with sense of purpose and meaning in life $(\beta=0.792, p$ value $=0.0001)$. When the two domains

Table 2 Reliability of $\mathrm{HK}-\mathrm{NCl}$

\begin{tabular}{lllll}
$\begin{array}{l}\text { HK-NCI total } \\
\text { and subscores }\end{array}$ & & Mean \pm SD & $\begin{array}{l}\text { Cronbach's } \\
\boldsymbol{\alpha}\end{array}$ & $\begin{array}{l}\text { Intra-class correlation } \\
\mathbf{( 9 5 \%} \mathbf{C l})\end{array}$ \\
\hline HK-NCl-Total & $3.8 \pm 0.5$ & 0.813 & $0.701(0.497$ to 0.832) \\
\hline HK-NCl-SC & $3.5 \pm 0.7$ & 0.763 & - \\
\hline HK-NCl-NB & $4.2 \pm 0.5$ & 0.715 & - \\
\hline
\end{tabular}

*Sample size for test-retest reliability was 38 .

HK-NCl, Hong Kong version of Neighbourhood Cohesion Instrument (15 items); NB, neighbourhood belonging (items 9, 10, $11,12,13,14$ and 15); SC, social cohesion (items 1, 2, 3, 4, 5, 6, 7 and 8). 


\begin{tabular}{|c|c|c|}
\hline \multirow{2}{*}{$\begin{array}{l}\mathrm{HK}-\mathrm{NCI} \text { total and } \\
\text { subscores }\end{array}$} & \multicolumn{2}{|c|}{ Pearson's correlation coefficients } \\
\hline & SCS & BSCS \\
\hline HK-NCI-Total & $0.635^{\star}$ & $0.612^{*}$ \\
\hline HK-NCl-SC & $0.575^{*}$ & $0.500^{*}$ \\
\hline HK-NCI-NB & $0.515^{\star}$ & $0.576^{*}$ \\
\hline
\end{tabular}

${ }^{*} P$ value $<0.001$.

BSCS, Brief Sense of Community Scale; HK-NCl, Hong Kong version of Neighbourhood Cohesion Instrument (15 items); NB, neighbourhood belonging; SC, social cohesion; SCS, Social Cohesion Scale.

of neighbourhood social cohesion were considered separately, both domains were positively associated with subjective well-being. Nevertheless, 'neighbourhood belonging' was more strongly associated with subjective well-being $\quad(\beta=0.780-1.308, \quad p$ values $=0.0001-<0.0001)$ than 'social cohesion' $(\beta=0.475-0.641$, $p$ values $=0.0028$ 0.0004) (table 4).

There were no significant age and sex differences on the three dimensions of subjective well-being. Stratified analyses indicated that the association between neighbourhood social cohesion and subjective well-being remained significant for all subgroups ('young-old' or 'old-old', men vs women, all $\mathrm{p}$ values $<0.05)$. Nevertheless, neighbourhood social cohesion was more strongly associated with all three dimensions of subjective wellbeing in 'young-old' subgroup, and with sense of purpose and meaning in life for women (table 5).

\section{DISCUSSION}

Research on the effects of neighbourhood social cohesion on older people's well-being is in its infancy. Therefore, we examined the psychometric properties of the HK-NCI, and related it to three dimensions of subjective well-being including life satisfaction, feelings of happiness and sense of purpose and meaning in life in a survey among community-dwelling older Chinese people. Input from a panel of experts and elderly volunteers indicated that all translated items of the HK-NCI were well understood. Psychometric testing supported the reliability and validity of the HK-NCI. Furthermore, neighbourhood social cohesion, as measured by the HK-NCI, was positively associated with the three dimensions of subjective well-being, after controlling the effects of individual-level and neighbourhood-level characteristics.

Consistent with previous studies that found associations between neighbourhood social cohesion and well-being, ${ }^{16-20}$ the results of this study reinforce the importance of neighbourhood social cohesion, a social contextual factor, in enhancing subjective well-being in older people. When we examined the associations of neighbourhood social cohesion with each of the dimension of subjective well-being, we found that the effect of neighbourhood social cohesion on life satisfaction and feelings of happiness was stronger than that on sense of purpose and meaning in life. These findings, however, are in contrast to the findings of a recent European study suggesting that physiological functioning is more strongly influenced by cohesion than life satisfaction and feelings of happiness. ${ }^{20}$ The differences between the results

Table 4 Association of subjective well-being and Hong Kong version of-Neighbourhood Cohesion Instrument total and subscores

\begin{tabular}{|c|c|c|c|c|c|}
\hline \multirow{2}{*}{$\begin{array}{l}\mathrm{HK}-\mathrm{NCl} \text { total and } \\
\text { subscores }\end{array}$} & \multirow[b]{2}{*}{ Subjective well-being } & \multirow{2}{*}{$\begin{array}{l}\text { Model 1 } \\
\beta \text { (P value) }\end{array}$} & \multirow{2}{*}{$\begin{array}{l}\text { Model } 2 \\
\beta \text { (P value) }\end{array}$} & \multirow{2}{*}{$\begin{array}{l}\text { Model } 3 \\
\beta \text { ( } P \text { value) }\end{array}$} & \multirow{2}{*}{$\begin{array}{l}\text { Model } 4 \\
\beta \text { (P value) }\end{array}$} \\
\hline & & & & & \\
\hline \multirow[t]{2}{*}{ HK-NCl-Total } & Life satisfaction & $1.146(<0.0001)$ & $1.091(<0.0001)$ & $1.088(<0.0001)$ & $1.079(<0.0001)$ \\
\hline & Sense of purpose and meaning in life & $0.942(<0.0001)$ & $0.794(<0.0001)$ & $0.795(<0.0001)$ & $0.792(0.0001)$ \\
\hline \multirow[t]{2}{*}{ HK-NCI-SC } & Life satisfaction & $0.645(0.0001)$ & $0.646(0.0003)$ & $0.638(0.0004)$ & $0.641(0.0004)$ \\
\hline & Sense of purpose and meaning in life & $0.502(0.0009)$ & $0.469(0.0024)$ & $0.469(0.0031)$ & $0.475(0.0028)$ \\
\hline \multirow[t]{3}{*}{$\mathrm{HK}-\mathrm{NCl}-\mathrm{NB}$} & Life satisfaction & $1.183(<0.0001)$ & $1.100(<0.0001)$ & $1.094(<0.0001)$ & $1.079(<0.0001)$ \\
\hline & Feelings of happiness & $1.456(<0.0001)$ & $1.314(<0.0001)$ & $1.327(<0.0001)$ & $1.308(<0.0001)$ \\
\hline & Sense of purpose and meaning in life & $1.034(<0.0001)$ & $0.806(<0.0001)$ & $0.797(<0.0001)$ & $0.780(0.0001)$ \\
\hline
\end{tabular}

Model 1: Crude model of hierarchical linear regression (clustering for seven neighbourhoods).

Model 2: Hierarchical linear regression model (clustering for seven neighbourhoods) adjusted for age, sex, marital status, education, employment status, income, type of housing and length of residence.

Model 3: Hierarchical linear regression model (clustering for seven neighbourhoods) adjusted for age, sex, marital status, education, employment status, income, type of housing, length of residence, current smoker, current drinker, physical activities and medical history.

Model 4: Hierarchical linear regression model (clustering for seven neighbourhoods) adjusted for age, sex, marital status, education, employment status, income, type of housing, length of residence, current smoker, current drinker, physical activities, medical history, geographic size, number of older persons, number of elderly and social centres.

HK-NCl, Hong Kong version of Neighbourhood Cohesion Instrument); NB, neighbourhood belonging; SC, social cohesion. 
Table 5 Association of subjective well-being and Hong Kong version of Neighbourhood Cohesion Instrument score by age group and sex

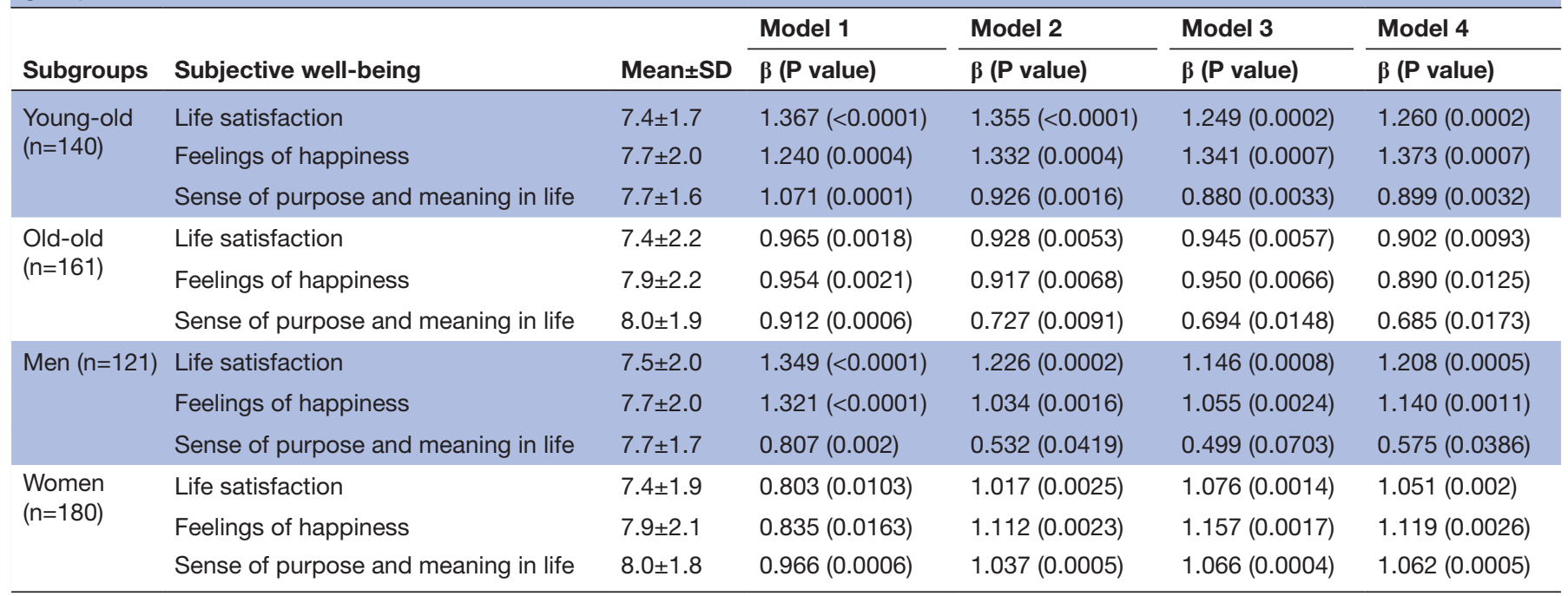

Model 1: Crude model of hierarchical linear regression (clustering for seven neighbourhoods).

Model 2: Hierarchical linear regression model (clustering for seven neighbourhoods) adjusted for sex (for the age-stratified analysis only), age (for the sex-stratified analysis only), marital status, education, employment status, income, type of housing and length of residence.

Model 3: Hierarchical linear regression model (clustering for seven neighbourhoods) adjusted for sex (for the age-stratified analysis only), age (for the sex-stratified analysis only), marital status, education, employment status, income, type of housing, length of residence, current smoker, current drinker, physical activities and medical history.

Model 4: Hierarchical linear regression model (clustering for seven neighbourhoods) adjusted for sex (for the age-stratified analysis only), age (for the sex-stratified analysis only), marital status, education, employment status, income, type of housing, length of residence, current smoker, current drinker, physical activities, medical history, geographic size, number of older persons, number of elderly and social centres.

could be related to the cross-cultural differences in social participation, psychological beliefs and subjective wellbeing of the study populations. Nevertheless, our findings and those in the literature emphasise the importance of considering cross-cultural differences in the role of neighbourhood social cohesion on subjective well-being in older people.

When we examined the associations of the two domains of neighbourhood social cohesion (ie, social cohesion and neighbourhood belonging) and the three dimensions of subjective well-being, we found that both domains of neighbourhood social cohesion were associated with subjective well-being. Furthermore, the association between neighbourhood belonging (compared with social cohesion) and subjective well-being was stronger. It has been suggested that feelings of belonging would influence an individual's identity and the extent to which they feel accepted, valued, respected, socially included and able to take on a role in society, which have been suggested as important predictors of overall health and well-being for older people. ${ }^{42}$ In a recent study examining the relationship between the perceived 'age-friendliness' with the eight age-friendly environment domains and selfrated health, 'respect and social inclusion' was the social domain most strongly associated with self-rated health in older people in Hong Kong. ${ }^{43}$ Therefore, interventions that promote sense of belonging, respect, and inclusion for older people have the potential to significantly improve older people's well-being.
Another important finding is that consistent associations of neighbourhood social cohesion and subjective well-being were found in both 'young-old' and 'oldold' subgroups and in both men and women. In other words, neighbourhood social cohesion is beneficial to all subgroups, be it 'young-old' or 'old-old', men or women. However, some differences in the magnitude of the associations were found between the subgroups. The 'young-old' subgroup benefited more from higher levels of neighbourhood social cohesion than the 'oldold' subgroup in all dimensions of subjective well-being. On the other hand, women benefited more from higher levels of neighbourhood social cohesion than men in eudaemonia well-being. A possible explanation for these findings could be that 'young-old' persons and women are more likely than 'old-old' persons (particularly those who are frail) and men to participate in community activities, which can bring numerous benefits (eg, enhancing social network and sense of competence and control, providing opportunities to learn new things), ${ }^{44}$ and thereby resulting in greater socially cohesive attitudes and subjective well-being. Our results are consistent with the results of a previous study where the buffering effect of neighbourhood cohesion on daily stress were stronger in younger adults when compared with the middle-age and older adults living in the USA. ${ }^{17}$ Statistics from a baseline assessment of the age-friendliness of Sha Tin and Tai Po districts in Hong Kong with over 700 respondents aged 60 and above revealed that women were found to 
be more likely to attend elderly community centres than men $(52.8 \%$ vs $28.4 \%) .{ }^{45}$ Qualitative data regarding older people's perspectives on social participation from seven focus groups conducted in 2018 with 38 community-dwelling older people in Hong Kong (mean age, 64.9) also revealed that older men are more reluctant to participate in community activities because they considered that the activities tend to be more appealing to women (unpublished data). Therefore, strategies to promote neighbourhood social cohesion among older people should take the potential age and gender differences into consideration.

The strength of this study lies in the multiple dimensions of subjective well-being measured including evaluative, hedonic, and eudaemonic well-being and the ability to control for a broad range of individual-level and neighbourhood-level confounding factors. Nevertheless, the present study has several limitations. The study was cross-sectional in design and therefore unable to establish casual associations between neighbourhood social cohesion and subjective well-being. The results were subject to selection bias as sociable people might be more likely to participate in this study. Individuals that are most frail and who consider themselves to be in a very poor state of health might have been neglected as these individuals are more likely to remain at home than those that are in a better state of physical and mental health. Self-reported and subjective measurements might cause information bias. People with poor health and well-being might view the world pessimistically and report their neighbourhood cohesion level lower than actual level. Finally, information on levels of perceived social support (such as patterns of contact among friends, families and spouses) that may affect subjective well-being at older ages were not available.

In conclusion, our findings suggest that the HK-NCI has adequate levels of internal consistency and test-retest reliability and can be used in studies of neighbourhood social cohesion in older Chinese people. Additionally, neighbourhood social cohesion was associated with better life evaluation, more positive emotions and higher levels of purpose and meaning in life, demonstrating the importance of neighbourhood social cohesion for subjective well-being among community-dwelling older Chinese people living in Hong Kong. Therefore, high levels of neighbourhood social cohesion may be one of the best ways of promoting subjective well-being in older people. The results of this study also pave the path for further research to examine the potential pathways by which perceived neighbourhood social cohesion may enhance subjective well-being. Further studies should also explore the determinants of neighbourhood social cohesion in an attempt to identify effective strategies to improve subjective well-being in older people.

Contributors RY: Conceptualisation, data analysis, and manuscript writing. OC: Data collection and data analysis. JL: Data analysis. CT: Data acquisition and manuscript review. KL: Data acquisition. JC: Literature review. JW:
Conceptualisation and manuscript review. All authors read and approved the manuscript.

Funding This work was supported by the Direct Grant for Research 2016/2017 (2016.044) of the Chinese University of Hong Kong.

Competing interests None declared.

Patient consent for publication Not required.

Ethics approval The study was approved by the Survey and Behavioral Research Ethics Committee of the Chinese University of Hong Kong (026-16). The study was performed in compliance with the Declaration of Helsinki.

Provenance and peer review Not commissioned; externally peer reviewed.

Data sharing statement The data sets generated during and/or analysed during the current study are not publicly available.

Open access This is an open access article distributed in accordance with the Creative Commons Attribution Non Commercial (CC BY-NC 4.0) license, which permits others to distribute, remix, adapt, build upon this work non-commercially, and license their derivative works on different terms, provided the original work is properly cited, appropriate credit is given, any changes made indicated, and the use is non-commercial. See: http://creativecommons.org/licenses/by-nc/4.0/.

\section{REFERENCES}

1. Andrew MK, Fisk JD, Rockwood K. Psychological well-being in relation to frailty: a frailty identity crisis? Int Psychogeriatr 2012;24:1347-53.

2. Boyle PA, Buchman AS, Barnes LL, et al. Effect of a purpose in life on risk of incident Alzheimer disease and mild cognitive impairment in community-dwelling older persons. Arch Gen Psychiatry 2010;67:304-10.

3. Boyle PA, Barnes LL, Buchman AS, et al. Purpose in life is associated with mortality among community-dwelling older persons. Psychosom Med 2009;71:574-9.

4. Diener E, Chan MY. Happy people live longer: subjective well-being contributes to health and longevity. Appl Psychol 2011;3:1-43.

5. Kaplan GA, Shema SJ, Leite CM. Socioeconomic determinants of psychological well-being: the role of income, income change, and income sources during the course of 29 years. Ann Epidemiol 2008;18:531-7.

6. Kawachi I, Berkman L. Social cohesion, social capital, and health. Social Epidemiology 2000:174-90.

7. Chan J, To H-P, Chan E. Reconsidering social cohesion: developing a definition and analytical framework for empirical research. Soc Indic Res 2006;75:273-302.

8. Schiefer D, van der Noll J. The essentials of social cohesion: a literature review. Soc Indic Res 2017;132:579-603.

9. Bjornstrom EE, Ralston ML, Kuhl DC. Social cohesion and self-rated health: The moderating effect of neighborhood physical disorder. Am J Community Psychol 2013;52(3-4):302-12.

10. Cramm JM, Nieboer AP. Relationships between frailty, neighborhood security, social cohesion and sense of belonging among communitydwelling older people. Geriatr Gerontol Int 2013;13:759-63.

11. Kim ES, Hawes AM, Smith J. Perceived neighbourhood social cohesion and myocardial infarction. J Epidemiol Community Health 2014;68:1020-6.

12. Kim ES, Park N, Peterson C. Perceived neighborhood social cohesion and stroke. Soc Sci Med 2013;97:49-55.

13. Inoue S, Yorifuji T, Takao S, et al. Social cohesion and mortality: a survival analysis of older adults in Japan. Am J Public Health 2013;103:e60-e66.

14. Echeverría S, Diez-Roux AV, Shea S, et al. Associations of neighborhood problems and neighborhood social cohesion with mental health and health behaviors: the Multi-Ethnic Study of Atherosclerosis. Health Place 2008;14:853-65.

15. Jones $R$, Heim $D$, Hunter $S$, et al. The relative influence of neighbourhood incivilities, cognitive social capital, club membership and individual characteristics on positive mental health. Health Place 2014;28:187-93.

16. Cramm JM, van Dijk HM, Nieboer AP. The importance of neighborhood social cohesion and social capital for the well being of older adults in the community. Gerontologist 2013;53:142-52

17. Robinette JW, Charles ST, Mogle JA, et al. Neighborhood cohesion and daily well-being: results from a diary study. Soc Sci Med 2013;96:174-82.

18. Elliott J, Gale CR, Parsons S, et al. Neighbourhood cohesion and mental wellbeing among older adults: a mixed methods approach. Soc Sci Med 2014;107:44-51. 
19. Cramm JM, Nieboer AP. Social cohesion and belonging predict the well-being of community-dwelling older people. BMC Geriatr 2015;15:30.

20. Delhey J, Dragolov G. Happier together. Social cohesion and subjective well-being in Europe. Int J Psychol 2016;51:163-76.

21. Kim ES, Kawachi I. Perceived neighborhood social cohesion and preventive healthcare use. Am J Prev Med 2017;53:e35-e40.

22. Momtaz YA, Haron SA, Ibrahim R, et al. Social embeddedness as a mechanism for linking social cohesion to well-being among older adults: moderating effect of gender. Clin Interv Aging 2014;9:863-70.

23. Gardner PJ. Natural neighborhood networks - Important social networks in the lives of older adults aging in place. J Aging Stud 2011;25:263-71.

24. Walker RB, Hiller JE. Places and health: a qualitative study to explore how older women living alone perceive the social and physical dimensions of their neighbourhoods. Soc Sci Med 2007;65:1154-65.

25. Murayama H, Nishi M, Nofuji $\mathrm{Y}$, et al. Longitudinal association between neighborhood cohesion and depressive mood in old age: A Japanese prospective study. Health Place 2015;34:270-8.

26. Fone D, White J, Farewell D, et al. Effect of neighbourhood deprivation and social cohesion on mental health inequality: a multilevel population-based longitudinal study. Psychol Med 2014:44:2449-60.

27. Kellaher L, Peace S, Holland C. Environment, identity and old age -quality of life or a life of quality? In: Walker A, Hennessy $\mathrm{CH}$, eds. Growing older: quality of life in older age. Maidenhead: Open University Press, 2004:60-80.

28. Philips DR, Siu OL, Ago Y, et al; Ageing and the urban environment. In: Andrews GJ, Philips DR, eds. Ageing and place. Abingdon: Routledge, 2005:147-63.

29. Steptoe A, Deaton A, Stone AA. Subjective wellbeing, health, and ageing. Lancet 2015;385:640-8.

30. Woo J, Wong H, Yu R, et al. Report on AgeWatch Index for Hong Kong. 2016;2014.

31. Buckner JC. The development of an instrument to measure neighborhood cohesion. Am J Community Psychol 1988;16:771-91.

32. Sampson RJ, Raudenbush SW, Earls F. Neighborhoods and violent crime: a multilevel study of collective efficacy. Science 1997;277:918-24.

33. Smith J, Fisher G, Ryan L, et al. Psychosocial and lifestyle questionnaire 2006 - 2010. Survey Research Center, Institute for Social Research. 2013.
34. Tomioka K, Kurumatani N, Hosoi H. Age and gender differences in the association between social participation and instrumental activities of daily living among community-dwelling elderly. BMC Geriatr 2017:17:99.

35. Yu R, Cheung O, Lau K, et al. Associations between perceived neighborhood walkability and walking time, wellbeing, and loneliness in community-dwelling older Chinese people in Hong Kong. Int J Environ Res Public Health 2017;14:1199.

36. Census and Statistics Department. Hong Kong 2016 Population By-census - Summary Results. Hong Kong Special Adminstrative Region. 2017.

37. Fone D, Dunstan F, Lloyd K, et al. Does social cohesion modify the association between area income deprivation and mental health? A multilevel analysis. Int J Epidemiol 2007;36:338-45.

38. Fone DL, Farewell DM, Dunstan FD. An ecometric analysis of neighbourhood cohesion. Popul Health Metr 2006;4:17.

39. Ch L, Hsu PH, Hsu SY. Assessing the application of the neighborhood cohesion instrument to community research in East Asia. J Community Psychol 2011;39:1031-9.

40. Huang $\mathrm{Y}$, Wong $\mathrm{H}$. Impacts of Sense of Community and Satisfaction with Governmental Recovery on Psychological Status of the Wenchuan Earthquake Survivors. Soc Indic Res 2014;117:421-36.

41. The Organisation for Economic Co-operation and Development (OECD). OECD guidelines on measuring subjective well-being: OECD publishing. 2013.

42. World Health Organisation (WHO). Social determinants of health: the solid facts. Copenhagen, Denmark. 2003.

43. Yu R, Wong M, Woo J. Perceptions of neighborhood environment, sense of community, and self-rated health: an age-friendly city project in Hong Kong. J Urban Health 2018.

44. Morrow-Howell N, Hinterlong J, Rozario PA, et al. Effects of volunteering on the well-being of older adults. J Gerontol B Psychol Sci Soc Sci 2003;58:S137-S145.

45. Jockey Club Institute of Ageing of the Chinese University of Hong Kong. Jockey Club Age-friendly City Project baseline assessment report - Sha Tin. 2016. https://www.jcafc.hk/images/baseline findings/Sha_Tin_Baseline_Assessment_Report.pdf

46. Jockey Club Institute of Ageing of the Chinese University of Hong Kong. Jockey Club Age-friendly City Project baseline assessment report - Tai Po. 2016. https://www.jcafc.hk/images/baseline_findings/ Tai_Po_Baseline_Assessment_Report.pdf. 